\title{
Análisis sectorial y regional del ciclo de vida de las firmas colombianas en el periodo 1995- 2000: un modelo datos de panel
}

\author{
Marleny Cardona Acevedo \\ Carlos Andrés Cano GamboA*
}

\begin{abstract}
The specificity of industrial development in a region is not only a matter of evolution and adaptive abilities, but also of taking advantage of the local conditions as well as the creation of the territorial model relationships at a local level. The purpose of this paper is to recognise the structural elements that determine the life cycle of Colombian companies. The measurement is carried out through a panel data model that allows us to build relationships between industrial organisation, geographical and social variables in the interpretation of life cycle in 19 productive sectors and three regions in Colombia.
\end{abstract}

Keywords: life cycle, territoriality, productive enterprises, industrial localisation.

\section{Resumen}

La especificidad del desarrollo industrial en las regiones no es un asunto sólo de evolución y de capacidades de adaptación, sino que busca el aprovechamiento de las condiciones locales y la generación de relaciones de un modelo territorial en un ambiente local. El propósito de este artículo es reconocer los determinantes estructurales del ciclo de vida de las firmas colombianas. La medición se hace a través de un modelo datos de panel, que permite la construcción de relaciones entre las variables de organización industrial, geográficas y sociales en la interpretación del ciclo de vida en 19 sectores productivos y tres regiones colombianas.

Palabras clave: ciclo de vida, territorialidad, firmas productivas, localización industrial.

* Estudios Sectoriales y Territoriales, Universidad Eafit de Medellín. Correos-e: marca@eafit.edu.co y ccanogam@eafit.edu.co. 


\section{Introducción ${ }^{1}$}

El territorio, escenario de localización de firmas, responde a la flexibilidad de los procesos sociales y económicos que potencian u obstaculizan la continuidad de los encadenamientos productivos, que trascienden los límites fijados administrativamente y las mismas relaciones sociales. ${ }^{2}$ El territorio es una construcción social que da pie a las dinámicas económicas y sociales tanto internas como externas, a las relaciones y estructuras de poder, a las manifestaciones culturales de la población y a las restricciones y potencialidades en la oferta ambiental que le imprimen rasgos característicos.

La dinámica industrial, como expresión del crecimiento, se refleja en el proceso de acumulación en dos niveles: 1) acumulación de capital físico y 2) acumulación de capital humano; ambas son condiciones del desarrollo. Los territorios, y en ellos las empresas, actúan en forma individual y colectiva participando en sistemas regionales que enfrentan fuertes competencias y generan la recomposición y el diseño de instrumentos de política para responder a los modelos productivos, donde la organización industrial y la dinámica regional, en forma conjunta, son expresión de las interrelaciones sociales en la localidad.

En este contexto, las firmas productivas aparecen como el mecanismo por el cual se estructuran las relaciones inter e intrasectoriales; ${ }^{3}$ en ellas, las decisiones pasan primero por el territorio, el cual posibilita y define las relaciones productivas. De manera similar, el espacio geográfico sufre procesos de cambio por la concentración industrial, la lógica de acumulación y la competencia local, nacional y global en una relación firma-territorio, donde sus dinámicas reestructuran y transforman la espacialidad industrial.

\footnotetext{
${ }^{1}$ La investigación base de este trabajo es: Ciclo de vida y localización espacial de las firmas en Colombia 1995-2000, realizada en la Universidad Eafit de Medellín (Colombia), por el Grupo de Estudios Sectoriales y Territoriales (ESYT), durante 2003. La investigación contó con la participación de Ana Rocío Osorio, a quien se agradecen sus aportes durante todo el proceso. También agradecemos a Marcela Orozco por su colaboración.

${ }^{2} \mathrm{La}$ instancia regional se convierte en un punto clave para la formulación de políticas que consideran la diversidad y la heterogeneidad, y sobre las cuales puede realizarse una evaluación de impactos de la organización espacial de las firmas.

${ }^{3}$ Los convenios, acuerdos y tratados de libre comercio son expresión de las nuevas dinámicas en los territorios. Se expresan, por un lado, en la generación de firmas localizadas espacialmente, y, por el otro, en la refuncionalización del Estado en favor de la política económica como directriz para participar en las cadenas de producción y comercialización.
} 
El objeto de estudio -las firmas en el territorio-, sin embargo, no es nuevo. La literatura revisada como antecedente muestra una aproximación a la dinámica industrial desde los enfoques tradicionales del desarrollo regional. Entre los estudios que invitan al replanteamiento de los análisis regionales y las políticas de localización industrial, ciclo de vida y emprendimiento están, en la esfera internacional, los liderados por Acs y Audretsch (1989, 1994, 1998), Feldman y Audretsch (1998), Roper y Love (1999) y Audretsch y Fritsch (1999); y en el ámbito de América Latina y Colombia, los de Durán et al. (1998), Burachik (2000), Cardona y Ángel (1999), Cardona et al. (2001), Cardona, Osorio y Cano (2003), Cepal (2000) y Lora (2001).

Las economías regionales resurgen motivando el desarrollo de identidades e interdependencias sociales, económicas y culturales entre los territorios, con estrategias generadas para la inserción en los mercados de los productos regionales a partir de las cuales emergen formas de organización del trabajo y ocurren cambios en la forma de producir que son importantes para las políticas empresariales y gubernamentales en los territorios. ${ }^{4}$

En la dinámica regional se han establecido lógicas que van de lo social a lo económico y viceversa, cuyos resultados se expresan en cuatro comportamientos básicos: 1) firmas y regiones que ganan, 2) firmas que ganan y regiones que pierden, 3) firmas que pierden y regiones que ganan y 4) firmas y regiones que pierden.

En el estudio de estas dimensiones se construye un objeto de estudio complejo, dinámico y con múltiples aristas, que se reúnen en dos unidades de análisis: 1) el espacio sectorial (la firma) y 2) el espacio geográfico (la región), con un punto de encuentro que denominamos ciclo de vida y localización espacial de la industria.

En el espacio sectorial, el concepto de empresa (firma) encierra una multiplicidad de nociones que pueden ser entendidas a su vez con complementariedad. ${ }^{5}$ En el espacio geográfico, la rela-

${ }^{4}$ Así, la región en el marco de la globalización es un espacio de interés en el cual cobran importancia las economías locales, en particular, como expresión de la superposición de los procesos de descentralización y vaciamiento de poder del Estado central.

Así, por ejemplo, para Tirole (1997: 15) la empresa (firma) es aquella capaz de producir (o vender) con más eficiencia de lo que lo harían sus partes constituidas actuando por separado. Schumpeter (1975: 84) define la empresa como la realización de nuevas combinaciones, y a los empresarios, como los individuos encargados de dirigirla; por eso integra la definición de empresario a la de innovador, tanto así que el carácter de emprendedor se pierde una vez que se inicia el negocio y se empieza a producir. Méndez y Caravaca (1996: 35) consideran a la firma como una entidad con capacidad de decisión, gestión y administración, que presenta una determinada estructura interna y declara un 
ción ciudad-región ha ido reforzándose en cada una de las etapas de la evolución económica y social, al grado de ser difícil referirse hoy a la economía local sin una visión de economía de área metropolitana. ${ }^{6}$

Este artículo analiza la dinámica industrial y sectorial con la discusión teórica sobre el ciclo de vida y la localización industrial de las firmas colombianas durante el periodo 1995-2000, por medio de variables de organización industrial, geográficas y sociales, y la formulación de un modelo datos de panel regional y otro sectorial. ${ }^{7}$

El estudio del ciclo de vida industrial ${ }^{8}$ representa la dinámica del surgimiento y desaparición de firmas en el tiempo. El proceso consiste en una intensa entrada de nuevas empresas que buscan formarse un espacio en una industria introduciendo innovaciones en productos y procesos que les permiten generar las barreras de entrada al sector. ${ }^{9}$

El análisis de las unidades productivas debe hacerse considerando no sólo un cierto tamaño o un sector en particular, sino también el marco de la organización industrial y su entorno es-

domicilio o razón social, aunque la localización de sus actividades pueda situarse en uno o varios establecimientos en lugares diversos. En este trabajo se asume la firma como una unidad sectorial integrada por recursos humanos, financieros y físicos que ofrece un bien terminado; está sujeta a ajustes permanentes ante cambios en las disposiciones legales y políticas; busca reducir costos de transacción y está conformada por individuos que toman decisiones racionales, donde la información no puede ser transmitida sin costos; la empresa no persigue un objetivo único y constituye coaliciones entre participantes con intereses muchas veces divergentes.

${ }^{6}$ La región alude a un territorio y a la dotación de recursos productivos. En ella ocurre un conjunto de interacciones que conforman un sistema compuesto por subsistemas productivos, institucionales y culturales, que encierran un cúmulo de relaciones tales como capital-trabajo, los flujos de intercambio, las relaciones monetarias y las pautas de comportamiento social.

${ }^{7}$ La dinámica industrial se explica desde el ciclo de vida industrial como parte fundamental del proceso de desarrollo. La innovación, la generación de empleo y las actividades de cooperación son elementos esenciales para su entendimiento. En este tipo de análisis algunos autores otorgan mayor poder explicativo al nivel macroeconómico espacial; otros se concentran en el análisis microeconómico, en particular en la teoría de la organización industrial.

${ }^{8}$ En este documento, el ciclo de vida industrial es calculado como la diferencia entre el surgimiento y la desaparición de las firmas en cada sector y en cada región, según la información suministrada por las distintas cámaras de comercio de cada región en Colombia.

${ }^{9}$ Los estudios precedentes a esta investigación han establecido que las micro, pequeñas y medianas empresas (mipymes) tienen un ciclo de vida industrial inestable y de menor duración que el de las grandes empresas. El reconocimiento de las diferencias entre las grandes y las pequeñas empresas facilita la mejor comprensión de la realidad de la base empresarial del país, la construcción de teoría económica relativa al crecimiento económico nacional y la recuperación del papel de los empresarios como dinamizadores de la actividad económica. 
pacial. Las estrategias empresariales son determinantes en el ciclo de vida de las firmas; su objetivo común es la generación de ventajas competitivas que aseguren a las firmas beneficios a largo plazo. A continuación se estudian el contexto económico y los determinantes estructurales del ciclo de vida de las firmas en 19 sectores productivos y tres regiones colombianas: ${ }^{10}$ BogotáSoacha, Cali-Yumbo y Medellín-Valle de Aburrá. ${ }^{11}$

\section{Contexto económico de las unidades productivas en Colombia}

El proceso de industrialización colombiano y los patrones de acumulación sobre los cuales se ha desarrollado transcurren de un modo más o menos similar al del resto de los países de América Latina. Pueden distinguirse, en este proceso, dos etapas: 1) una etapa sustitutiva de importaciones, que si bien se inició desde la década de 1930, adquirió su configuración precisa en la década de 1950 y mantuvo su carácter estrictamente sustitutivo hasta 1967 ; 2) la otra etapa, que puede distinguirse a partir de la década de 1970, sin abandonar su carácter sustitutivo, apoyó la expansión productiva basada en la exportación de manufacturas, lo que modificó, en parte, las condiciones de acumulación desarrolladas desde los años de la década de $1950 .{ }^{12}$

${ }^{10}$ Los resultados de la investigación Ciclo de vida y localización espacial de las firmas en Colombia 1995-2000 son para seis regiones colombianas. En este artículo, los resultados se presentan para las tres arriba mencionadas. Los resultados globales se presentan en el anexo del artículo.

${ }^{11}$ La información del modelo datos de panel sobre la dinámica del ciclo de vida es el número de registros de instalación y liquidación de firmas año por año realizados en seis regiones, y para los siguientes sectores: fabricación de productos alimenticios, excepto bebidas (311-312); industria de bebidas (313); fabricación de textiles (321); fabricación de prendas de vestir, excepto calzado (322); fabricación de calzado y sus partes, excepto el de caucho o plástico (324); industria de la madera y productos de la madera y el corcho, excepto muebles (331); fabricación de muebles y accesorios, excepto los que son principalmente metálicos (332); fabricación de papel y productos de papel (341); imprentas, editoriales e industrias conexas (342); fabricación de sustancias químicas industriales (351); fabricación de otros productos químicos (352); fabricación de productos de caucho (355); fabricación de productos plásticos (356); fabricación de otros productos minerales no metálicos (369); fabricación de productos metálicos, exceptuando maquinaria y equipo (381); construcción de maquinaria, exceptuando la eléctrica (382); construcción de equipo y material de transporte (384), y otras industrias manufactureras (390).

${ }^{12}$ A partir de la década de 1970, pocas empresas industriales colombianas crecieron realmente más allá de las oportunidades del mercado interior. Colombia siguió viviendo de las exportaciones primarias de café, carbón, petróleo y otros productos, protegiendo el mercado interior y manteniendo una industria que para la década de 1980 era pequeña, poco competitiva y con una baja participación en el mercado internacional. 
Entre 1974 y 1991, la industria colombiana registró un agotamiento del proceso de sustitución de importaciones. El comportamiento industrial en esos años estuvo marcado por la sucesión de fases cortas de expansión (1975-1980), crisis (1981-1983) y leve recuperación (1984-1989). Según Lotero (1998), en ese periodo, caracterizado por algunos analistas como de crisis estructural de la industria, se presentaron acontecimientos y cambios en el manejo económico que, sin duda, afectaron el desempeño sectorial. Entre otros, las bonanzas de precios del café (1976-1978 y 1985-1987), las políticas de ajuste fiscal (19741978 y 1984-1986), la liberación parcial del régimen de comercio exterior (1978-1982) y su reversión posterior (1982-1984) y la fuerte caída de la tasa de cambio real (1978-1982). ${ }^{13}$

Sin duda, la estructura de la economía colombiana cambió entre los decenios de 1980 y $1990 .{ }^{14} \mathrm{Al}$ finalizar la década de 1980 apareció el modelo de liberalización económica, que aplicó aperturas de choque en el supuesto de que el mercado internacional haría una distribución justa de los recursos y de que los países en desarrollo crecerían rápidamente gracias a las nuevas condiciones resultantes. De otra parte, también hubo cambios en la composición de las exportaciones totales entre un periodo y otro. ${ }^{15}$

${ }_{13}$ De acuerdo con Lotero (1998), en Colombia se habían introducido algunos ajustes y llevado a la práctica procesos de reconversión industrial, sin que por ello puedan catalogarse como estructurales. A estas peculiaridades del manejo macroeconómico y del comportamiento de la industria, se suma la del sistema urbano-regional del país. Colombia ha contado con un sistema descentralizado y relativamente flexible que ha permitido que a lo largo de la historia del desarrollo económico se produzcan ajustes parciales de cierta magnitud.

${ }^{14}$ Así, en la economía colombiana viene ganando participación el sector de servicios, incluidos los servicios financieros, los cuales pasaron de representar $26.7 \%$ del producto interno bruto (PIB) en 1980, a 30.7\% en 1998. Igualmente, la explotación de minas y canteras, que incluye hidrocarburos, ganó participación en la producción en ese decenio, de $1.3 \%$ a $4.9 \%$. Por el contrario, la agricultura y la industria han mostrado una tendencia decreciente dentro de la producción total, especialmente acentuada desde 1994. En efecto, la agricultura pasó de representar 22.7\% del producto en 1980 , a $20.6 \%$ en 1993 y $18.4 \%$ en 1998. La participación de la industria en el PIB pasó de representar 22.4\% en 1980, a 17.9\% en 1998 (información recopilada en el Departamento Administrativo Nacional de Estadística de Colombia, DANE).

${ }^{15}$ En efecto, según Echeverry (1999), en 1980 el café exportado equivalía a 59\% de las exportaciones totales; a partir de entonces empezó a perder participación hasta representar $17.5 \%$ en 1998 . Esto hacía que la economía colombiana estuviera más expuesta a las variaciones del precio internacional del café. Por otra parte, se observa un aumento sustancial en la participación de las exportaciones de hidrocarburos, es decir, de carbón y petróleo. De hecho, en 1980 las exportaciones por este concepto representaron 2.9\% del total exportado, mientras que en 1998 aumentaron a 30.3\%. Al mismo tiempo, otras exportaciones no tradicionales como las flores y el banano representaron $2.4 \%$ en 1980, y aumentaron a 9.5\% del total en 1998 . 
La apertura económica, la reforma al sector financiero, las modificaciones del régimen cambiario, la promulgación de una nueva Constitución política en 1991 -con los consiguientes cambios institucionales, que entre otros factores determinaron en gran parte la evolución del gasto público- modificaron el panorama económico que había en el decenio de 1980. Por lo tanto, en el análisis de los ciclos económicos es indispensable tener en cuenta los cambios estructurales causados por los factores mencionados.

La economía colombiana enfrentó un proceso de desaceleración del crecimiento desde 1996 y de recesión a partir del último trimestre de 1998. Después de haber registrado tasas anuales de crecimiento superiores a $5 \%$ real anual promedio entre 1993 y 1995, el crecimiento calculado de 1998 fue de 0.6\% (DANE), el crecimiento para el primer trimestre de 1999 fue de $-5.9 \%$, y lo fue de un nivel similar para el primer semestre del año 2000. Por su parte, la tasa de desempleo alcanzó niveles cercanos a 20\%. En este contexto global, se aprecia un deterioro significativo, en los últimos años, en las cifras del sector productivo privado colombiano.

Desde el análisis de la organización industrial, tanto en el periodo preapertura como en el de postapertura, las micro, pequeñas y medianas empresas (mipymes) ${ }^{16}$ en Colombia generaron cerca de $40 \%$ de la producción bruta y 34\% del valor agregado nacional (Echeverri, 1999). ${ }^{17}$ Sin embargo, se observaron diferencias importantes a lo largo del periodo 1985-1995 en cuanto al comportamiento por tamaño de empresa: 1) la mediana empresa se destacó por haber presentado mayor estabilidad en su crecimiento (ciclos de auge y recesión menos pronunciados), y 2) la pequeña empresa ha seguido una dinámica independiente que en varios años se aleja del patrón de crecimiento de la industria global en Colombia (véase gráfica I).

En el cuadro 1 se observa que la participación por tamaño de empresas en los últimos 20 años no se ha modificado mucho en

${ }^{16}$ La microempresa se define en Colombia como aquella constituida con uno a 10 trabajadores; la pequeña empresa, aquella con 11 a 50 trabajadores, y la mediana empresa, con 51 a 200 trabajadores.

${ }^{17}$ En el periodo postapertura (1991-1995), según el Departamento Nacional de Planeación (DNP) de Colombia, el mejor comportamiento promedio lo presentó la mediana empresa, que sostuvo un crecimiento anual de $6.4 \%$ en promedio, frente a $4.8 \%$ de la gran empresa y a $4.4 \%$ de la pequeña empresa. La dinámica de la mediana empresa en ese periodo se debió al desempeño positivo de los bienes de capital, los bienes intermedios y los bienes de consumo no durables, mientras que la acentuada caída promedio en la producción de la pequeña empresa se presentó por descensos en la producción de los bienes de consumo duradero y no duradero. 


\section{Gráfica I}

Patrón de crecimiento de la industria global 1980-2000

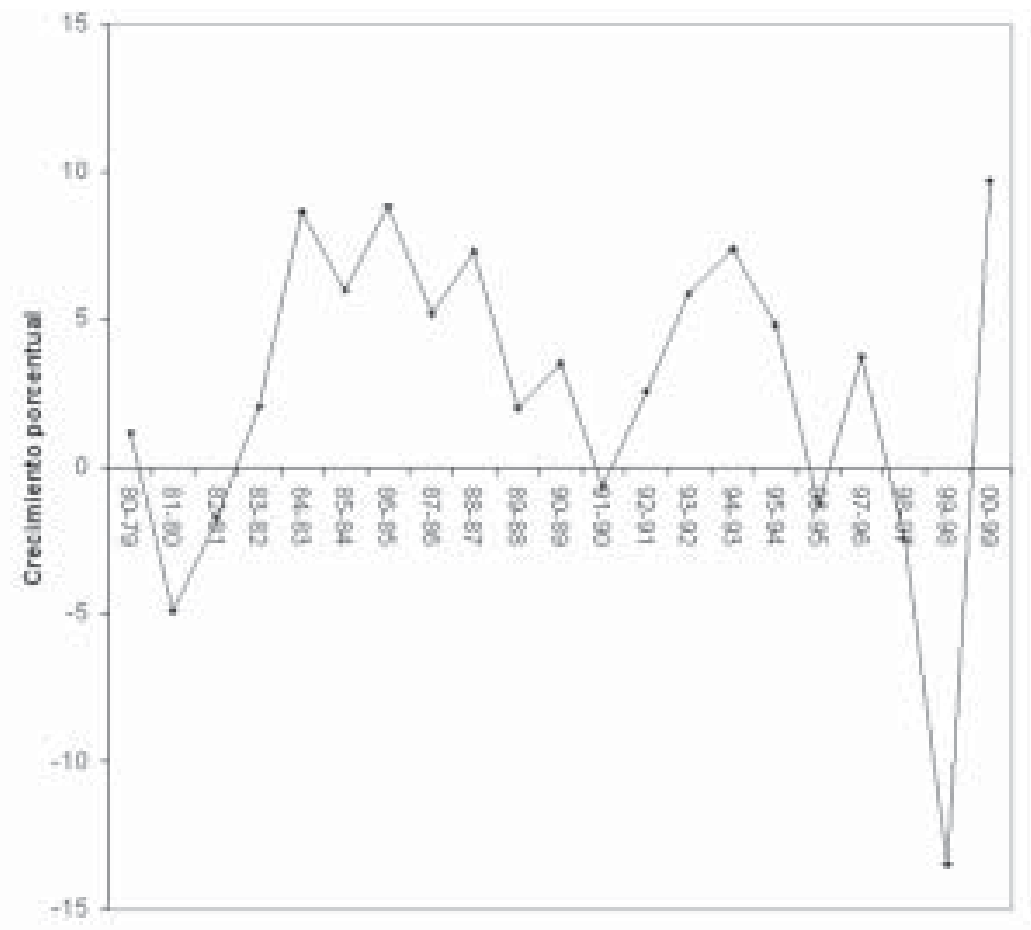

Fuente: Departamento Administrativo Nacional de Estadística (2003).

Colombia. La microempresa y la pequeña empresa se han mantenido en niveles promedio de $70 \%$, son así las de mayor ponderación. La mediana empresa colabora con $22 \%$ en promedio, mientras que la gran empresa representa para el sistema económico colombiano 7\%, en promedio.

Partiendo de este panorama, la investigación realizó un análisis de acuerdo con el modelo datos de panel para determinar las variables de organización industrial, geográficas y sociales que han incidido en el ciclo de vida de las firmas colombianas en el periodo 1995-2000.

\section{Consideraciones metodológicas del modelo datos de panel}

El sistema económico depende de la interacción entre las variables económicas en la sociedad y el espacio. Por eso la propuesta metodológica considera correr el modelo datos de panel en dos etapas. La primera relaciona la influencia de las variables geo- 


\section{Cuadro 1}

Participación en el número de establecimientos según tamaño de empresa 1985-1995

\begin{tabular}{lrrrc}
\hline \multicolumn{1}{c}{ Año } & Pequeña & Mediana & Grande & Total \\
\hline 1985 & $70.9 \%$ & $22 \%$ & $7.1 \%$ & $100 \%$ \\
1986 & $71.3 \%$ & $21.7 \%$ & $6.9 \%$ & $100 \%$ \\
1987 & $71.2 \%$ & $21.7 \%$ & $7.1 \%$ & $100 \%$ \\
1988 & $72.1 \%$ & $21.2 \%$ & $6.6 \%$ & $100 \%$ \\
1989 & $72.8 \%$ & $20.7 \%$ & $6.4 \%$ & $100 \%$ \\
1990 & $72.0 \%$ & $21.3 \%$ & $6.7 \%$ & $100 \%$ \\
Promedio 1985-1990 & $71.7 \%$ & $21.5 \%$ & $6.8 \%$ & $100 \%$ \\
1991 & $70.7 \%$ & $22.2 \%$ & $7.1 \%$ & $100 \%$ \\
1992 & $70.7 \%$ & $22.1 \%$ & $7.2 \%$ & $100 \%$ \\
1993 & $68.6 \%$ & $23.6 \%$ & $7.7 \%$ & $100 \%$ \\
1994 & $68.1 \%$ & $23.9 \%$ & $8.0 \%$ & $100 \%$ \\
1995 & $69.7 \%$ & $22.8 \%$ & $7.5 \%$ & $100 \%$ \\
Promedio 1991-1995 & $69.6 \%$ & $22.9 \%$ & $7.5 \%$ & $100 \%$ \\
1996 & $69.6 \%$ & $23.2 \%$ & $7.2 \%$ & $100 \%$ \\
1997 & $72.4 \%$ & $21.1 \%$ & $6.5 \%$ & $100 \%$ \\
1998 & $72.6 \%$ & $21.0 \%$ & $6.4 \%$ & $100 \%$ \\
1999 & $74.4 \%$ & $19.6 \%$ & $6.0 \%$ & $100 \%$ \\
2000 & $74.6 \%$ & $19.5 \%$ & $6.0 \%$ & $100 \%$ \\
Promedio 1996-2000 & $72.7 \%$ & $20.9 \%$ & $6.4 \%$ & $100 \%$ \\
\hline
\end{tabular}

Pequeña empresa (incluye la microempresa): entre 10 y 49 trabajadores; mediana empresa, entre 50 y 199 trabajadores; y gran empresa, más de 200 empleados. FUENTE: Echeverri (1999).

gráficas específicas en el ciclo de vida de las firmas; y la segunda establece el impacto de las características industriales sobre los factores geográficos. Dichos modelos están asociados a las siguientes ecuaciones:
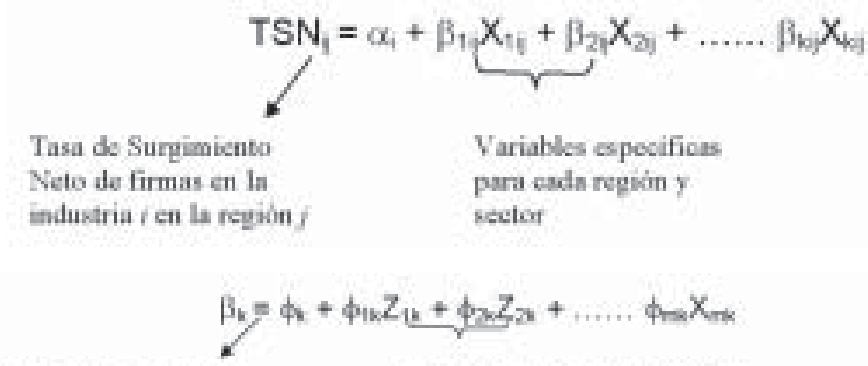

Valar del purinetro estimado de la cereción I iv valides de infindrias exuecifican

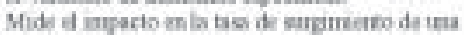
indrotria por tan carntoo at tea rariakle gecerates estecifiea 
El objeto de este estudio son las variables que influyeron en la dinámica del ciclo de vida de las firmas de Colombia en el periodo 1995-2000. Las variables seleccionadas como explicativas de este fenómeno se dividen entre las asociadas al sector, que se expresan como variables de organización industrial, y las asociadas al territorio, ${ }^{18}$ llamadas variables geográficas específicas; además de variables sociales.

El ciclo de vida de las firmas es la variable dependiente sobre la cual se analizan las relaciones respecto a las variables explicativas. En las variables de organización industrial se tienen en cuenta: 1) intensidad del capital, ${ }^{19}$ 2) relación capital producto, ${ }^{20} 3$ ) costo laboral unitario ${ }^{21}$ y 4) salario promedio industrial. ${ }^{22}$ En las variables geográficas están: 5) tasa de desempleo, 6) tamaño de la población, 7) índice de tasa de cambio real y 8) índice de localización industrial. ${ }^{23}$ Las variables sociales son: 9) logro educativo y 10) tasa de homicidios.

Estructura y localización de las firmas son parte del mismo asunto y pertenecen a un proceso de evolución donde se condicionan variables que interactúan entre sí y permiten la consolidación o el declive de los aparatos productivos. Estas variables pueden ser tanto externas como inherentes al proceso sectorial.

${ }^{18}$ En las investigaciones del Grupo de Estudios Sectoriales y Territoriales de la Universidad Eafit de Medellín, se ha evidenciado que el territorio tiene alto impacto en las condiciones del crecimiento industrial. En la investigación ya referida (Cardona, Osorio y Cano, 2003), se confirmó que el ciclo de vida, la estructura y localización de las firmas no son indiferentes al paso del tiempo, sino que permanecen en un proceso de evolución donde se condicionan variables que interactúan entre sí permitiendo consolidación o declive de los aparatos productivos. Estas variables pueden ser tanto externas como inherentes al proceso productivo sectorial y regional.

${ }^{19}$ Relación entre el valor de los activos fijos reales de cada industria $\left(K_{i j t}\right)$ (deflactado por el índice de precios al productor [IPP], base 1998) y el total de personal ocupado en cada una de ellas $\left(N_{i j t}\right)$. Incluye personal permanente y temporal.

${ }^{20}$ Muestra la razón entre el valor de los activos fijos reales $\left(K_{i j t}\right)$ y el valor agregado real de cada industria $\left(V A_{i i t}\right)$, deflactados por el IPP, base 1998.

${ }^{21}$ Relación entre la remuneración laboral unitaria y la productividad laboral unitaria de cada industria. Éstas se definen, respectivamente, como la razón de sueldos y salarios de la industria, y la razón producción bruta real de la industria; la primera deflactada por el índice de precios al consumidor (IPC), base 1998, y la segunda, por el IPP, base 1998. En otras palabras, se definen como la razón sueldos y salarios $\left(W_{i j t}\right)$, y la producción industrial $\left(Y_{i j i}\right)$ para cada sector considerado.

${ }^{22}$ Razón entre el valor de los sueldos y salarios para el total de la industria manufacturera de cada área metropolitana $\left(W_{j t}\right)$ deflactado por el IPC, base 1998, y el total del personal ocupado en la industria $\left(N_{i t}\right)$. Incluye personal permanente y temporal.

${ }^{23}$ Está basado en el número de establecimientos, de manera que da cuenta del grado de aglomeración de los sectores económicos en las regiones. Se define como la razón entre la proporción de establecimientos $\left(E_{i j t}\right)$ de cada sector y región, respecto al total de establecimientos del total de la industria manufacturera en cada región $\left(E_{m i t}\right)$ y la misma proporción, pero calculada para el total nacional $(n)$. 
La transformación estructural de las relaciones de producción y de poder en los sistemas económicos forma parte de la dinámica de una nueva sociedad, donde la necesidad de ser entes flexibles y competitivos es un proceso esencial de la economía.

El desarrollo en la década de 1970 sobre la especificación de modelos econométricos regionales propició un número importante de aplicaciones a regiones de Estados Unidos y países europeos. Algunos modelos son unirregionales y analizan las relaciones entre diversas variables en una región a lo largo del tiempo. Los modelos multirregionales analizan las diferencias entre los distintos niveles de desarrollo de varias regiones, bien elaborando un modelo con una serie temporal de cada región y comparando los resultados, bien mediante modelos interregionales que se obtienen con una muestra conjunta de varias regiones en un momento determinado, modelo cross-section, o en varios momentos mediante un pooling o muestra combinada.

El estudio Surgimiento de firmas regionales colombianas (19952000) (Cardona, et al., 2001) encuentra en tres regiones colombianas y tres sectores económicos (alimentos, textil y confecciones) crecimiento exponencial en el surgimiento de firmas entre 1995 y 2000 . Se concluye que la instalación de firmas en las regiones y los sectores es diferente y por tanto requiere distintas formas de intervención en Colombia. Mientras en los modelos sectoriales las variables más significativas se asocian a los factores geográficos y regionales, en los modelos regionales prevalece la dinámica en la organización industrial dentro de las localidades.

El análisis del ciclo de vida de las firmas colombianas muestra los cambios en el tiempo de las variables estructurales de la industria en las regiones. Se establece que: 1) el modelo datos de panel sectorial da cuenta del efecto regional sobre el ciclo de vida en un mismo sector industrial, y 2) el modelo datos de panel regional analiza la estructura industrial de cada región en términos de la información sobre los sectores analizados. En total, el modelo está conformado por tres regiones, 19 sectores, 10 variables explicativas y una dependiente: surgimiento neto de las firmas, ${ }^{24}$ como se aprecia en el esquema I.

${ }^{24}$ Las bases de datos y su estructuración para la modelación generaron algunas dificultades en la calidad y cantidad de los datos, lo que limitó el tipo de método que podría utilizarse en el momento de realizar las predicciones. En este caso, se encontró: 1) poca homogeneización de la información disponible; 2) diferencias regionales y sectoriales en el tipo de variables construidas; 3) en el ámbito de las economías regionales en Colombia no existe información oficial por tamaño de firmas; 4) la construcción del dato, y 5) la heterogeneidad estructural de las regiones y de los sectores en Colombia. 


\section{Esquema I}

Proceso metodológico en la medición del ciclo de vida de las firmas colombianas en el periodo 1995-2000

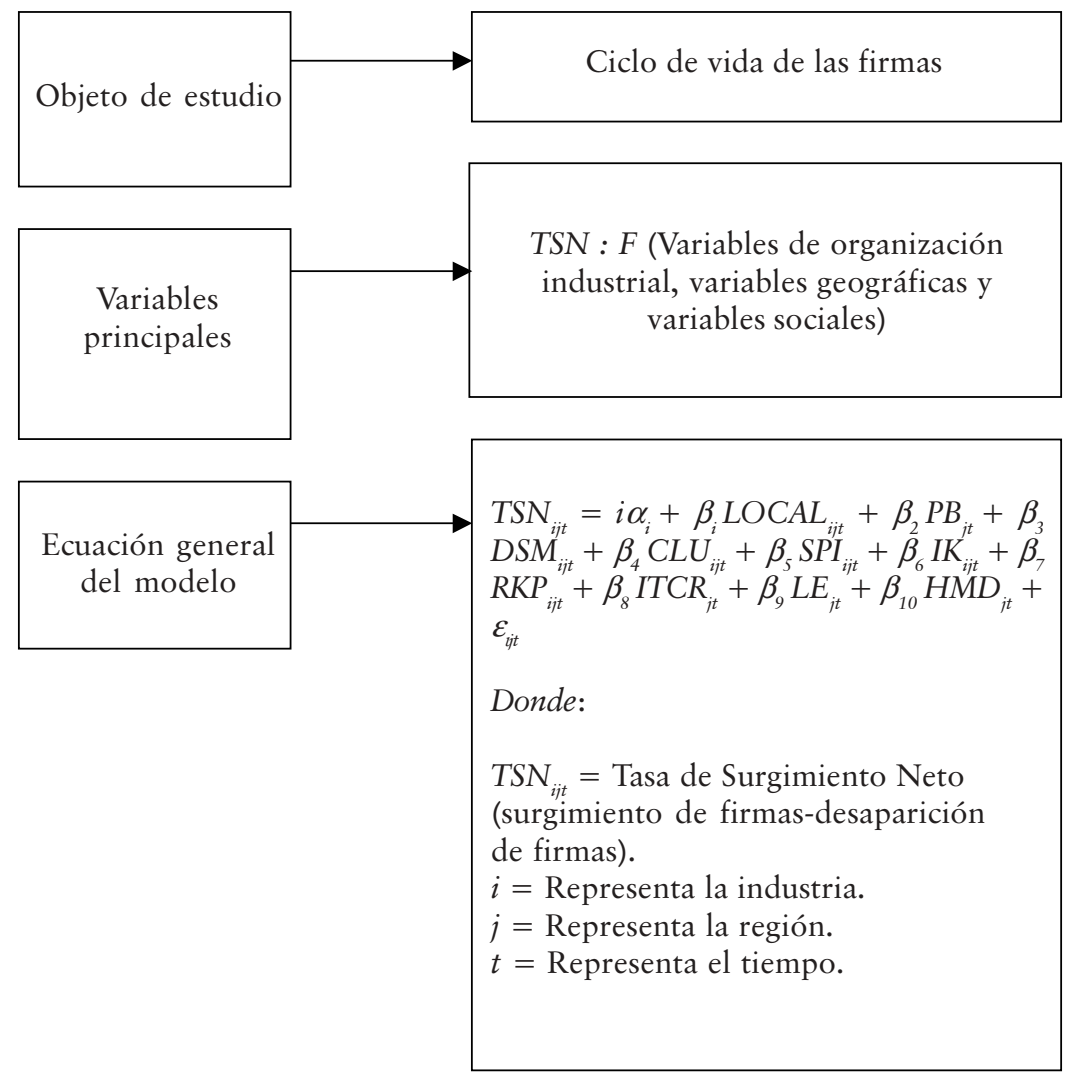

El modelo de ciclo de vida de las firmas colombianas surgió del trabajo Labor Market Approach utilizado por Audretsch y Fritsch (1999). Además se consideró la metodología empleada por Armington y Acs (2000), quienes examinan el papel del capital humano, la capacitación, el nivel de educación y el nivel empresarial en el surgimiento de firmas. El resultado empírico da cuenta de diferencias en la tasa de formación de nuevas empresas en las regiones, explicadas principalmente por la densidad industrial, el crecimiento poblacional y el ingreso per cápita. Estos resultados son consistentes con las competencias laborales y la intensidad del capital con el efecto spillovers que se tiene en el 
sistema económico. ${ }^{25}$ También se atendieron los trabajos de Keeble y Walker (1994) y Davidson et al. (1994) en la metodología de la construcción de las variables utilizadas en el modelo.

En la formulación, el modelo datos de panel considera que los errores variantes a través del tiempo no están correlacionados con valores presentes y pasados de ciertas variables condicionantes, de modo que son predeterminados respecto a los errores variantes en el tiempo. Este tipo de modelo satisface la condición de momentos secuencial, como se expone a continuación:

$$
E\left(v_{\mathrm{ir}} \mid z_{i 1}, \ldots, z_{i}\right)=0
$$

El modelo es el siguiente:

$$
y_{n t}=\alpha y_{i t}+x_{n i}^{\prime} \beta+\eta_{t}+b_{n}
$$

Junto con el supuesto:

$$
E\left(v_{k} \mid y_{i}^{t}, x_{i}^{t}, \eta_{j}\right)=0
$$

Donde

$$
y_{i}^{t}=\left(y_{i n}, y_{i 2, \ldots,} y_{j}\right) \text { y } x_{j}^{s}=\left(x_{i}, \ldots, x_{j}\right)
$$

es una versión secuencial del modelo de ajuste parcial propuesto por Arellano y Bond (1991). Un ejemplo del modelo anterior es:

$$
y_{i f}=\alpha y_{i j}+\beta_{0} x_{a}+\beta_{1} x_{i t}+\eta_{i}+v_{a}
$$

Donde:

$$
(t=1, \ldots, T ; i=1, \ldots, N)
$$

Una versión general del modelo (ecuación 2) es la siguiente:

$$
y_{i f}=\omega_{v} \delta+\eta_{i}+v_{i f}
$$

${ }^{25}$ Las variables utilizadas en este modelo fueron: el tamaño de las firmas (como proxy de la estructura de la industria en las regiones), el crecimiento poblacional, el ingreso per cápita, la tasa de desempleo, la concentración industrial y el logro educativo. 
Con el supuesto:

$$
E\left(v_{m} \mid z_{i}^{r}\right)=0
$$

La ecuación 7 es una versión general del modelo de la ecuación 4 (Arellano y Bond, 1991), con $z_{i}^{t}=\left(z_{i 1}, \ldots, z_{i t}\right)$. La estimación del método generalizado de momentos (GMM) de $\delta$ en 7 (Mátyás, 1999) se basa en la siguiente condición de momentos:

$$
E\left[z_{j}^{\prime}\left(v_{w+1}-v_{n}\right)\right]=0 \quad(t=1, \ldots, T-1)
$$

O utilizando desviaciones ortogonales, según lo planteado por Arellano y Bover (1995):

$$
E\left(z^{\prime} v_{k}^{*}\right)=0 \quad(t=1, \ldots, T-1)
$$

Una expresión compacta que integra las ecuaciones 7 y 8 es la siguiente:

$$
E\left(z_{i}^{\prime} K u_{i}\right)=E\left[z_{i}^{\prime} K\left(y_{i}-W_{i} \delta\right)\right]=0
$$

Donde $K$ representa cualquier matriz de transformación triangular superior de $(T-1) * T$ con rango $(T-1)$ tal que $K \gamma=0$, donde $\gamma$ es un vector de unos de $T^{*} 1$. La ortogonalidad entre $K$ y $\gamma$ asegura que la transformación elimina el efecto fijo. $z_{i}$ es una matriz de bloques diagonales cuyo i-ésimo bloque está dado por $z_{i}^{t}$; así:

$$
Z_{i}=\left(\begin{array}{ccc}
Z_{i}^{\gamma} & \cdots & 0 \\
\vdots & \ddots & \vdots \\
0 & \cdots & Z_{i}^{T-1^{\prime}}
\end{array}\right)
$$

Donde:

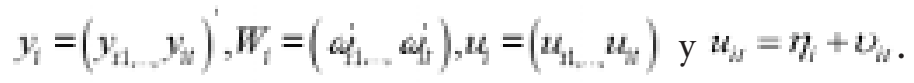

El estimador GMM de $\delta$ se obtiene minimizando

$$
S_{N}(\dot{\partial})=\left[\frac{1}{N} \sum_{j=1}^{N} z_{i} K\left(y_{t}-W_{i} \partial\right)\right] A_{N}\left[z_{i} K\left(y_{i}-W_{i} \partial\right)\right]
$$


y queda como resultado:

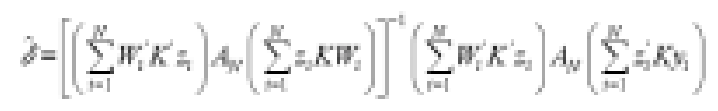

Tal como lo demuestra Hansen (1982), la elección de $A_{N}$ debe ser tal que sea proporcional a la inversa de la matriz de covarianzas de la condición de ortogonalidad. Dados los elementos teóricos discutidos anteriormente, la ecuación básica para el modelo datos de panel es la siguiente:

$$
\Delta y_{s}=\alpha y_{w}+x_{i w}^{\prime} \beta+\gamma_{t}+\eta_{t}+v_{s}
$$

Donde:

$$
i=1, \ldots, N \quad t=2, \ldots, T
$$

$\Delta Y_{i t}=$ Tasa de surgimiento neto de la industria $i$ en el periodo $t$. $x_{i t}=$ Representa un vector de variables explicativas clasificadas en: 1) organización industrial, 2) variables geográficas y 3) variables sociales.

$\gamma_{t}=$ Representa el efecto temporal que captura cambios en la productividad comunes a todos los sectores industriales.

La construcción del modelo y la base de datos fue un proceso que concentró la atención en el análisis del comportamiento de los resultados en las mediciones, teniendo en cuenta los delineamientos teóricos y la selección de las variables de acuerdo con criterios econométricos sobre los cuales se basaría la elección de las mejores estimaciones.

A continuación se muestran los resultados de los modelos, los cuales fueron validados ${ }^{26}$ mediante las pruebas de Hausman ${ }^{27}$ y Breusch y Pagan. ${ }^{28}$

${ }^{26} \mathrm{Si}$ los errores en niveles son serialmente independientes, presentarán en primeras diferencias correlación serial de orden 1, pero no de orden 2. Arellano y Bond (1991) desarrollan un test formal conocido como el estadístico =v (u) En la hipótesis nula de no correlación serial, este estadístico es calculado de los residuales en primeras diferencias, excepto cuando la estimación es en niveles. El estadístico $m_{j}$ está basado en la autocovarianza de orden $j-t h$ promedio, $r_{j}$, la cual está planteada por: $r_{j}=\frac{1}{T-3-j} \sum_{t \rightarrow+t j}^{T} r_{t}$, donde $r_{t j}=E\left(\Delta v_{i t} \Delta_{i, t-j}\right)$. En la hipótesis nula $H_{0}: r_{j}=0$, el estadístico está dado por $m_{i}+\frac{i}{-i}(j)$, donde $r_{j}$ es la contraparte muestral de $\vec{r}_{3}$. basado en los residuales en primeras diferencias

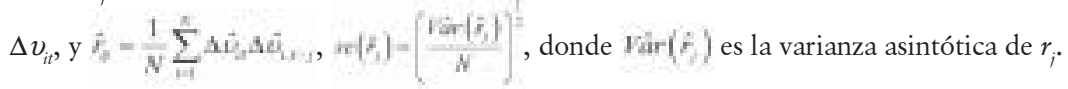




\section{Comportamiento de las variables de organización industrial, geográficas y sociales en los sectores industriales colombianos en el periodo 1995-2000}

La comprensión de la dinámica industrial pasa primero por el análisis del comportamiento de las variables elegidas para una propuesta de modelo estructural de la realidad industrial, y, segundo, por la aplicación del modelo y el reconocimiento de la realidad en él. Así, los resultados de la medición dan cuenta del surgimiento neto de las firmas, lo que se determinó como el número de firmas que surgen menos el número de las que se liquidan. De esta forma, una disminución del surgimiento o un incremento del total de firmas liquidadas generan un ciclo de vida menor; del mismo modo, un incremento del número de firmas

${ }^{27}$ El test de especificación de Hausman se utiliza para verificar la ortogonalidad de los efectos aleatorios y los regresores. Está basado en la idea de que en la hipótesis de no correlación, el modelo de mínimos cuadrados ordinarios en el modelo de variables dummies de mínimos cuadrados y el modelo de mínimos cuadrados generalizados son consistentes, pero el modelo de mínimos cuadrados ordinarios es ineficiente. La otra alternativa es que mínimos cuadrados ordinarios es consistente, pero mínimos cuadrados generalizados no lo es. De esta forma, en la hipótesis nula los dos estimadores podrían no diferir sistemáticamente, y el test puede estar basado en la diferencia.

$$
\operatorname{Var}(b-\hat{\beta})=\operatorname{Var}(b)+V \operatorname{ar}(\hat{\beta})-\operatorname{Cov}(b-\hat{\beta})-\operatorname{Cov}(b-\hat{\beta})
$$

El resultado esencial del test de Hausman es que la covarianza de un estimador eficiente con la diferencia de un estimador ineficiente es cero, lo que implica que:

$$
\operatorname{Cov}((b-\hat{\beta}), \hat{\beta})=\operatorname{Cov}(b, \hat{\beta})-\operatorname{Var}(\hat{\beta})=0
$$

o que:

$$
\operatorname{Cov}(b, \hat{\beta})=\operatorname{Var}(\hat{\beta})
$$
el test:

Insertando este resultado en (1) se produce la matriz de covarianza requerida para

$$
\operatorname{Var}(b-\hat{\beta})=\operatorname{Var}(\beta)-\operatorname{Var}(\hat{\beta})=\psi
$$

El test de chi-cuadrada está basada en el criterio Wald:

$$
W=\chi^{2}[K-1]=[b-\hat{\beta}]^{\prime} \psi^{-1}[b-\hat{\beta}]
$$

Para $\psi$ se utiliza la matriz de covarianzas estimadas del coeficiente del estimador del modelo de mínimos cuadrados de variables dummies y la matriz de covarianzas estimadas en el modelo de efectos aleatorios, excluyendo el término constante. En la hipótesis nula, $W$ tiene una distribución chi-cuadrada con $K-1$ grados de libertad (Greene, 2003: 300-302).

${ }^{28}$ El test para efectos aleatorios de Breusch y Pagan se presenta en un multiplicador de Lagrange basado en los residuales de los mínimos cuadrados ordinarios. La prueba contrasta las hipótesis: 
que surgen o la disminución del número de firmas que se liquidan generan un mayor ciclo de vida.

\subsection{Análisis sectorial de la industria colombiana en las dimensiones de organización industrial, geográfica, territorial y social}

El análisis de las unidades productivas debe hacerse considerando no sólo un cierto tamaño o un sector en particular, sino también el marco de organización y su entorno. Las estrategias empresariales y la organización espacial son determinantes en el ciclo de vida de las firmas; su objetivo común es el establecimiento de ventajas competitivas que aseguren a las firmas beneficios a largo plazo. $^{29}$

En la economía, como en las demás ciencias sociales, comúnmente se ha caído en el error de considerar que su campo de acción tiene que ver con la asignación y el acrecentamiento de los recursos materiales y tangibles, y, de esta manera, la confinan al estrecho campo del crecimiento, subvaluando la dimensión humana, que es la verdadera razón de ser del desarrollo. Si bien la identidad entre crecimiento y desarrollo está hoy en día en entredicho, no sólo desde la reflexión teórica sino también, y principalmente, desde la evidencia empírica, es necesario insistir en el carácter complejo del desarrollo y en la necesidad de una visión interdisciplinaria que permita esclarecer los componentes e identificar las variables significativas que deben considerarse.

En esta perspectiva pretenden otorgarse a la política económica objetivos sociales y tener siempre presentes sus implicaciones, así

$$
\begin{aligned}
& H_{o}: \sigma_{u}^{2}=0_{\rightarrow}\left(\operatorname{Corr}\left[\eta_{i t}, \eta_{i s}\right]=0\right) \\
& H_{1}: \sigma_{u}{ }^{2} \neq 0
\end{aligned}
$$

El test estadístico es:

$$
L M=\frac{n T}{2(T-1)}\left[\frac{\sum_{t=1}^{n}\left[\sum_{t=1}^{T} \ell_{i t}\right]^{2}}{\sum_{i=1}^{n} \sum_{t=1}^{n} \ell_{i t}^{2}}-1\right]^{2}=\frac{n T}{2(T-1)}\left[\frac{\sum_{t=1}^{n}\left(T \bar{\ell}_{i}\right)^{2}}{\sum_{i=1}^{n} \sum_{t=1}^{n} \ell^{2}{ }_{i t}}-1\right]^{2}
$$

En la hipótesis nula, $L M$ es distribuida como una chi-cuadrada con un grado de libertad.

${ }^{29}$ Méndez y Caravaca (1996) definen este tipo de ventajas como el dominio y control, por parte de una empresa, de una característica, habilidad, recurso o conocimiento que incrementa su eficiencia y le permite distanciarse de la competencia. Este aspecto supone que las empresas con ventajas competitivas logran tener un ciclo de vida mayor. 


\section{Cuadro 2}

Resultado de un modelo regional por sectores, de variables de organización industrial, geográficas y sociales para el análisis del ciclo de vida de las firmas colombianas 1995-2000

\begin{tabular}{|c|c|c|c|c|c|c|c|c|c|c|c|}
\hline Sector & $\bar{L}$ & SPI & $\mathrm{CLU}$ & $\overline{\mathrm{IK}}$ & RKP & $\mathrm{PB}$ & DSM & $\mathrm{LE}$ & HMD & ITCR & $\begin{array}{c}\mathrm{R} 2 \\
\text { Ajustado }\end{array}$ \\
\hline Alimentos y bebidas & + & + & - & + & + & + & + & + & - & - & 0.522 \\
\hline Textiles y calzado & - & + & - & - & - & - & + & + & - & + & 0.999 \\
\hline $\begin{array}{l}\text { de muebles } \\
\text { Papel e imprentas y }\end{array}$ & + & + & - & - & + & + & - & + & - & - & 0.999 \\
\hline editori & + & + & - & - & + & - & + & + & - & + & 0.397 \\
\hline $\begin{array}{l}\text { Químicos } \\
\text { Caucho y productos }\end{array}$ & + & - & + & - & - & + & - & - & - & - & 0.999 \\
\hline plásti & + & - & + & + & - & + & - & - & - & + & 0.997 \\
\hline $\begin{array}{l}\text { Minerales no metálicos } \\
\text { Metálicos, maquinaria, }\end{array}$ & + & + & - & - & + & + & + & - & + & - & 0.989 \\
\hline $\begin{array}{l}\text { construcción de equipo } \\
\text { Otras industrias }\end{array}$ & + & + & + & + & + & + & - & - & - & - & 0.999 \\
\hline manufactureras & + & + & + & + & - & + & - & - & - & - & 0.999 \\
\hline
\end{tabular}

El modelo incluyó estimaciones en desviaciones ortogonales.

Los errores estándar son robustos para heteroscedasticidad.

Los instrumentos utilizados en el modelo están en niveles.

El método de estimación es paneles incompletos o desbalanceados por efectos fijos. El contraste del multiplicador de Lagrange para el modelo de efectos aleatorios de Breusch y Pagan muestra evidencias en favor del modelo de componentes del error.

El contraste de Hausman valida el método utilizado.

como hacer explícita la contribución económica de la política social. A continuación presentamos los resultados obtenidos con dos variables sociales que tuvimos en cuenta en la modelación: tasa de homicidios (HMD) y logro educativo (LE) (véase cuadro 2).

En el caso del sector alimentos y bebidas se obtuvo que la variable logro educativo tenía influencia positiva en el ciclo, mientras que tasa de homicidios explica la reducción del surgimiento neto, lo que llevaría a establecer que altos niveles de homicidios repercuten negativamente en la madurez productiva de las firmas de este sector.

En el caso del sector textiles y calzado, el comportamiento de índice de tasa de cambio real (ITCR) permite consolidar el ciclo de vida, lo correcto con ampliación de mercados y diversificación exportadora lograda por las firmas textileras colombianas. El logro educativo (LE) también presenta el signo esperado. Al igual que en el sector alimentos y bebidas, una disminución de la tasa de homicidios $(\mathrm{TH})$ permite ampliar el ciclo de vida de las firmas.

La inclusión de la variable logro educativo (LE) busca aportar al modelo efectos con las calificaciones laborales que permitan pro- 
ductividad sectorial, lo que se espera influya en un mayor ciclo de vida de las firmas. Este comportamiento se observó, como ya se dijo, en los sectores alimentos y bebidas, textiles y calzado, madera y fabricación de muebles y papel e imprentas y editoriales. En el resto de los sectores analizados no se encuentra relación positiva entre el logro educativo y el surgimiento neto de las firmas.

El índice de tasa de cambio real (ITCR) explica, dentro del modelo, la apertura exportadora de los sectores, y se espera que un mayor índice permita mayor surgimiento neto de las firmas; en el caso contrario, dada la pérdida de competitividad vía tasa de cambio, hay una liquidación de firmas que se refleja en menores ciclos de vida. Se obtuvo: 1) que los sectores textilero, papel e imprentas y editoriales, y minerales no metálicos presentan relación positiva con el índice de tasa de cambio real; 2) los demás sectores no mejoran el surgimiento neto por medio del sector externo, o también puede ser que tengan una alta carga de deuda externa, lo que influye negativamente en su ciclo de vida al aumentar la tasa de cambio.

Finalmente, la medición del ciclo de vida considerando las tres dimensiones: organización industrial (salario promedio industrial, costo laboral unitario, intensidad del capital y relación capital producto), geográfica (índice de localización, tamaño de la población, índice de tasa de cambio real y tasa de desempleo) y social (logro educativo y tasa de homicidios), identifica la relación directa e inversa que tienen dichas variables. Por ejemplo: índice de localización y tamaño de la población son las variables con mayor incidencia directa, mientras que tasa de homicidios tiene una relación inversa; esto puede explicarse por el impacto en la capacidad productiva de las firmas; mientras que en relación capital producto, intensidad del capital y logro educativo, la correspondencia depende del tipo de sector analizado.

El territorio como escenario de localización de firmas responde hoy a los procesos de flexibilidad tanto productiva como socialmente; allí se potencia u obstaculiza la continuidad de los procesos productivos y sus encadenamientos. La relación firmaterritorio explica en parte la forma en que se han manifestado los procesos de reestructuración y las transformaciones espaciales de la dinámica industrial.

Una aproximación regional al objeto de estudio permite, por un lado, conocer el comportamiento sectorial dentro de una región, y, por otro lado, da cuenta de las diferencias en la estructura industrial interregional. A continuación se analizan modelos 
datos de panel para cada región, de forma similar a los realizados sectorialmente. ${ }^{30}$

\section{Modelo de datos de panel por regiones colombianas}

En la discusión desde las esferas sectorial y geográfica es permanente la relación de interdependencia entre firma y territorio, a la que se liga el desarrollo, como expresión de las potencialidades endógenas del territorio, a la dinámica industrial. El crecimiento en las firmas genera progreso económico; al mismo tiempo, condiciones macroeconómicas adecuadas permiten que las empresas puedan mantener su competitividad interna y externa.

El desarrollo aparece como un proceso intangible que depende de elementos tangibles (acumulación de capital físico y humano) y de una adecuada organización y estructura interna de las regiones, que garantice el establecimiento de unidades productivas que potencien el crecimiento territorial y el flujo de inversiones externas. Se plantea entonces el desarrollo como el efecto conjunto de factores exógenos y endógenos del territorio.

A continuación se presenta un análisis sectorial para cada región del estudio mediante un modelo que relaciona las variables de organización industrial, geográficas y sociales (véase cuadro 3).

\subsection{Análisis de los sectores en la región Bogotá-Soacha}

La localización es importante en el surgimiento neto de las firmas asentadas en Bogotá-Soacha, por las ventajas que genera el tamaño de la población y la condición de centro administrativo, político y económico. En este caso, la variable tasa de desempleo no suscita impacto positivo en el surgimiento de nuevos proyectos productivos.

Las variables de organización industrial no tienen relación estrecha; no obstante, el costo laboral unitario incide en el incremento del surgimiento neto de las firmas de la región BogotáSoacha, porque a menores costos laborales los empresarios obtienen ganancias relativas que se traducen en consolidación de su firma.

\footnotetext{
${ }^{30}$ Se consideran como unidades de sección cruzada la organización industrial: salario promedio industrial (SPI), costo laboral unitario (CLU), intensidad del capital (IK) y relación capital producto (RKP); variables geográficas: índice de localización (IL), tamaño de la población (PB), tasa de desempleo (DSM) e índice de tasa de cambio real (ITCR); y variables sociales: logro educativo (LE), y tasa de homicidios (HMD)
} 


\section{Cuadro 3}

Resultado de un modelo regional de variables de organización industrial y geográficas para el análisis del ciclo de vida de las firmas colombianas en el periodo 1995-2000

\begin{tabular}{|c|c|c|c|c|c|c|c|c|c|c|}
\hline Región & $\mathbb{L}$ & SPI & $\mathrm{CLU}$ & IK & RKP & $\mathrm{PB}$ & DSM & ITCR & $\begin{array}{c}\mathrm{R} 2 \\
\text { Ajustado }\end{array}$ & $\begin{array}{c}\mathrm{F} \\
\text { Estadístico }\end{array}$ \\
\hline oacha & + & + & - & - & + & + & - & - & 0.670 & 0.000 \\
\hline $\begin{array}{l}\text { Cali-Yumbo } \\
\text { Medellín-Valle }\end{array}$ & - & - & + & + & - & - & - & - & 0.856 & 0.000 \\
\hline del Aburrá & + & - & - & + & - & + & + & + & 0.969 & 0.000 \\
\hline
\end{tabular}

El modelo incluyó estimaciones en desviaciones ortogonales.

Los errores estándar son robustos para heteroscedasticidad.

Los instrumentos utilizados en el modelo están en niveles.

El método de estimación es paneles incompletos o desbalanceados por efectos fijos.

El contraste del multiplicador de Lagrange para el modelo de efectos aleatorios de

Breusch y Pagan muestra evidencias en favor del modelo de componentes del error.

El contraste de Hausman valida el método utilizado.

La variable índice de tasa de cambio real no muestra efectos en el ciclo de vida de las firmas, ya que una mejora de competitividad vía tasa de cambio no incide en el surgimiento neto. Este tipo de comportamiento se justificaría en que los empresarios de Bogotá-Soacha no han cifrado en la tendencia de la tasa de cambio sus posibilidades de exportar, por el contrario, han desarrollado ventajas dinámicas y métodos empresariales que los apartan del vaivén cambiario; otra razón podría encontrarse en el nivel de endeudamiento externo que tengan los empresarios exportadores de la región, ya que con incrementos de la tasa de cambio se genera mayor carga de deuda, lo que obstruye el proceso productivo y deriva en un alto porcentaje de liquidación de firmas, lo que se traduce en un menor surgimiento neto.

\subsection{Análisis de los sectores en la región Cali-Yumbo}

La localización en Cali-Yumbo no tiene relación positiva con surgimiento neto de las firmas, lo que muestra que los empresarios no se asientan en esta región por las posibilidades que les brinda; quizá lo hagan por decisiones de cultura, tradición o lazos familiares. La variable tamaño de la población tampoco incide positivamente en el ciclo de vida de las firmas.

Dados los resultados, puede decirse que en Cali-Yumbo el surgimiento de firmas se dinamiza por variables distintas de las de organización industrial y las geográficas, lo que implica que las políticas industriales son ineficientes o tienen bajo impacto. 


\subsection{Análisis de los sectores en la región Medellín-Valle del Aburrá}

En el caso de Medellín-Valle de Aburrá, de acuerdo con las variables seleccionadas para explicar el ciclo de vida, se evidencia una lógica regional importante, pues la variable que incide en un mayor surgimiento de firmas es índice de localización, se aprovechan así las condiciones locales y se genera en redes un modelo territorial en un ambiente local.

Además, se encontró que: 1) tamaño de la población, tasa de desempleo, costo laboral unitario, intensidad del capital e índice de tasa de cambio real tienen efectos positivos en el surgimiento de firmas en la región, y 2) las variables con un comportamiento contrario son: salario promedio industrial y relación capital producto.

\section{Datos de Panel por regiones colombianas: modelo de organización industrial, localización y variables sociales}

El territorio es más que un mero receptáculo o soporte físico de las actividades sociales, económicas y culturales del hombre; constituye un tejido social e histórico, resultado de las relaciones sociales que se expresan en diversas formas de uso, ocupación, apropiación y distribución. Las políticas sociales brindan posibilidades para el ordenamiento y desarrollo sostenible del territorio, mediante la planificación de las formas de aprovechamiento, su ocupación y la capacidad de integrar el sistema al conjunto de la población.

Para obtener consolidación y madurez de los aparatos productivos colombianos, no sólo hay que pensar en precios, capital y tecnología, sino también en la interacción social. En el siguiente modelo se incluyen las variables sociales, desde las cuales se busca entender la incidencia que presenta la situación social en el ciclo de vida de las firmas regionales, adicional a la localización y a la organización industrial (véase cuadro 4).

\subsection{Análisis de la región Bogotá-Soacha}

El índice de localización en la región de Bogotá-Soacha muestra economías de aglomeración. La población es un factor importante en este caso. Aparentemente, esta región no ha pasado el umbral de urbanización, lo que aún favorece el surgimiento de firmas, y se generan economías de escala que contribuyen a la 
consolidación de las firmas asentadas. Este resultado resalta el peso que posee la aglomeración de los factores respecto a su simple acumulación, que es además un catalizador para el crecimiento, pues contribuye, por un lado, a elevar la productividad al facilitar la combinación de factores y difusión de innovación y conocimiento, y, por otro, a la eficiencia por su incidencia en la reducción de costos de transporte, transacción e información para los agentes.

Bogotá-Soacha presenta signo positivo en la variable tamaño de la población, lo que indica lo significativo de este factor en la consolidación de las firmas que se localizan en la región. La existencia de economías de aglomeración y la relación directa que hay entre el surgimiento de firmas y el tamaño poblacional estarían indicando que esas economías de aglomeración se asocian a economías de urbanización.

El índice de localización sugiere que el número de empresas en el sector todavía no sobrepasa ciertas bondades de la aglomeración. Se postula como hipótesis que este índice, con signo positivo, podría ser indirectamente un indicador de mejor organización de los productores y, en general, de los actores que concurren en la producción para establecer mejores relaciones sociales entre organizaciones gremiales.

La tasa de desempleo, con signo negativo, explica cómo una mayor tasa de desempleo puede estar asociada a una menor entrada de nuevas firmas al mercado, en el sentido de que se reduce la posibilidad de consumo en el mercado por parte de las personas que quedan cesantes. Bogotá-Soacha, por ser el gran centro de consumo del país, ha alineado su propio crecimiento económico y el de los municipios aledaños.

Las variables de organización industrial resultan significativas, pero su aporte al surgimiento neto de las firmas es marginal y con poca incidencia, cuestión que no se esperaba a priori, ya que la región Bogotá-Soacha debería tener alta relación intensidad del capital y relación capital producto con la fase de consolidación de las firmas en el ciclo de vida. Este análisis se amplía a la variable externa índice de tasa de cambio real, la cual presentó signo negativo.

El análisis de las variables sociales presentó ciertas inconsistencias teóricas en relación con los resultados. El logro educativo no incide en el surgimiento de empresas, lo que llevaría a pensar que las firmas de la región no requieren trabajadores con alta calificación. 


\begin{tabular}{|c|c|c|c|c|c|c|c|c|c|c|c|}
\hline \multicolumn{12}{|c|}{$\begin{array}{l}\text { Cuadro } 4 \\
\text { Resultados de un modelo regional de variables de organización } \\
\text { industrial, geográficas y sociales para el análisis del ciclo de } \\
\text { vida de las firmas colombianas en el periodo 1995-2000 }\end{array}$} \\
\hline Región & $\mathbb{L}$ & & $\mathrm{Cu}$ & IK & RKP & $\mathrm{PB}$ & DSM & LEI & TCR & $\begin{array}{c}\mathrm{R} 2 \\
\text { ljustado }\end{array}$ & $\begin{array}{c}\mathrm{F} \\
\text { Estadístico }\end{array}$ \\
\hline Bog & + & - & - & 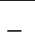 & - & & - & - & - & & \\
\hline $\mathrm{C}$ & - & 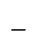 & + & 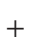 & - & - & - & + & + & & \\
\hline Medell & + & - & + & + & - & - & - & + & + & & 0.000 \\
\hline
\end{tabular}

El modelo incluyó estimaciones en desviaciones ortogonales.

Los errores estándar son robustos para heteroscedasticidad.

Los instrumentos utilizados en el modelo están dados en niveles.

El método de estimación es paneles incompletos o desbalanceados por efectos fijos.

El contraste del multiplicador de Lagrange para el modelo de efectos aleatorios de

Breusch y Pagan muestra evidencias en favor del modelo de componentes del error.

El contraste de Hausman valida el método utilizado.

\subsection{Análisis de la región Cali-Yumbo}

En los resultados de esta región destaca una relación inversa con el índice de localización, lo cual sugiere que las economías de aglomeración ocurren para un cierto tamaño de ciudades y de aglomeración de firmas. Esta región muestra que para los empresarios no es de relevancia el territorio donde se ubican sus firmas. Tal comportamiento es similar respecto al tamaño de la población: se revela que la magnitud del mercado local no tiene incidencia en el ciclo de vida de las firmas allí asentadas.

El desempleo obtiene un signo negativo, lo que significa que a un mayor nivel de desocupación corresponde una menor entrada de nuevas firmas al mercado y un mayor ritmo de liquidación, en el sentido de que se reduce la posibilidad de consumo por parte de las personas que quedan cesantes, y esto contribuye a reducir el ciclo de vida de las firmas de los sectores analizados.

Costo laboral unitario presentó incidencia directa en el surgimiento neto de las firmas, lo que representa relación positiva con el ciclo de vida que podría estar asociado a mayor grado de calificación de los trabajadores. De igual forma, relación capital producto presentó signo negativo, y es elocuente pues demuestra que en esta región el aporte del capital como factor productivo al valor agregado de la empresa es en alguna medida un indicador de poca eficiencia.

Las variables sociales presentaron relación positiva con el surgimiento neto; eso indica que en Cali-Yumbo la educación es 
un factor condicionante de los procesos de inserción del individuo en la sociedad del conocimiento, y que juega un papel fundamental en el ejercicio de la ciudadanía, ya que, con todas sus limitaciones, el sistema escolar constituye en esta región uno de los agentes de socialización que contribuye a la formación y al desarrollo de los individuos.

El índice de tasa de cambio real presentó relación positiva con el surgimiento neto, lo que demuestra que la actitud exportadora de los empresarios del valle del Cauca puede generarles sinergias positivas en un escenario de seguridad y con mayores logros educativos en sus trabajadores, lo cual permite un ciclo de vida prolongado de sus firmas.

\subsection{Análisis de la región Medellín-Valle de Aburrá}

Esta región presenta el índice de localización con signo positivo y alta significancia estadística que sería producto, por un lado, de estrategias empresariales diferenciales que interiorizan el valor de uso complejo del territorio en su afán por conseguir mejores niveles de competitividad; $y$, por el otro lado, del aprovechamiento de condiciones locales y la generación de redes en un modelo territorial. El desempleo es un flagelo que golpea el ciclo de vida de las firmas antioqueñas al reducir su estabilidad y producir mayores procesos de liquidación.

En cuanto a las variables de organización industrial se establece que, aunque todas ellas son significativas estadísticamente, no presentan relación estrecha con el ciclo de vida de las firmas. Caso contrario ocurre con la variable externa, donde una mayor tasa de cambio otorgaría a las firmas un ciclo extenso. Esto muestra que la ampliación de mercados externos con mayor competitividad permite mayores tasas de surgimiento de firmas e impide su liquidación, lo que prolonga su ciclo y les genera madurez productiva.

La variable social tiene un alto significado para esta región, dado que el logro educativo presentó signo positivo y alto nivel de significación estadística. Podría decirse que cuando se alcanza a una masa crítica de la población se contribuye a una mejor definición de las instituciones y de las reglas de juego colectivas, y que aumentos de las capacidades humanas permiten que las empresas accedan a mayores competencias laborales, lo que genera ventajas competitivas dentro de sus firmas y establece si- 
nergias positivas a la región. Esto repercutiría en mayores ciclos de vida de las firmas.

\section{Conclusiones}

El territorio, como espacio donde se localizan los sectores, se constituye en un aporte y soporte para elevar la eficacia de la gestión empresarial local. Es allí donde la dinámica productiva se vuelve eje de las políticas de fomento que elevan la capacidad para la asistencia técnica, el acceso a los canales de crédito y a la información.

En este estudio, el objetivo básico fue identificar los factores determinantes del ciclo de vida de las firmas (resta entre el surgimiento y la liquidación de firmas) y la distribución espacial de la industria manufacturera en Colombia en la segunda mitad de la década de los noventa. Se partió de que el ciclo de vida y la localización de los sectores es diferente y cambiante, y para comprobar lo anterior se hicieron mediciones con el modelo datos de panel por regiones y por sectores que permitieran observar el comportamiento a través del tiempo.

La medición evidenció que las fuerzas competitivas influyen directamente en el ciclo de vida y la localización industrial por medio de su relación con la estructura interna y con las condiciones que propician un potencial crecimiento o una etapa recesiva. Las condiciones que marcan la competencia influyen sobre la estructura y las estrategias de las firmas. La participación de esa competencia sobre los beneficios potenciales y el entorno que delimita el ciclo de vida de las firmas explica la existencia de barreras de entrada y salida, el grado de rivalidad entre las firmas existentes, la presión de los bienes sustitutos y complementarios y el poder de negociación existente en la cadena de comercialización.

En los resultados de los modelos del ciclo de vida se encontró que siendo las mismas variables medidas por sectores y por regiones, son distintos los resultados. Algunas variables que en la medición por regiones influyen directamente, en el análisis por sectores son inversas. Esto muestra el grado de heterogeneidad que presentan las regiones colombianas y la forma en que los determinantes inciden en el proceso de surgimiento neto.

El comportamiento de las variables de los sectores en las distintas regiones en términos de las dimensiones propuestas no presenta una lógica donde podamos separar impactos de la orga- 
nización industrial, por un lado, y de las variables geográficas, por el otro, sino unas relaciones entre las variables que las definen como determinantes del ciclo de vida en un territorio determinado. Por ejemplo: el comportamiento del tamaño de la población por economías de aglomeración tiene una relación positiva en Medellín-Valle de Aburrá, Bogotá-Soacha y Cali-Yumbo. El desarrollo tecnológico, visto a través de relación capital producto, mostró un impacto en el ciclo de vida de las firmas sólo en Bogotá-Soacha.

Estos resultados son importantes en el diseño de políticas locales para los sectores productivos en la industria. La distribución espacial de las actividades económicas y de la población es resultado de múltiples decisiones individuales y, por tanto, colectivas. La inclusión de variables sociales en un modelo de relaciones que tienen que ver con la teoría de la organización industrial (microeconomía) y la localización (mesoeconomía) adquiere relevancia, ya que agrega explicaciones de la realidad social del territorio al comportamiento sectorial.

En cuanto al análisis de localización, dicha variable explicó el aumento del ciclo de vida en las regiones Bogotá-Soacha y Medellín-Valle de Aburrá, mas no en Cali-Yumbo. Debe destacarse el comportamiento de esta variable en Medellín-Valle de Aburrá, pues muestra en todas las regresiones una alta significación. Es preocupante el comportamiento, por un lado, de la variable relación capital producto, ya que tiene signo inverso, por lo que posiblemente está restándose importancia al desarrollo tecnológico; y, por otro, de la variable tamaño de la población, que presenta el mismo signo, lo cual significa que la aglomeración no es determinante en el ciclo de vida de algunos sectores.

El ciclo de vida de las firmas no depende sólo de variables micro, asociadas a la organización industrial, sino también de variables sociales, que aunque son limitadas y tienen poca información, expresan algunas relaciones. Además, son necesarias para la consolidación y madurez de los aparatos productivos colombianos porque no sólo hay que pensar en precios, capital y tecnología, sino también en interacción social.

La estructura productiva de un territorio es el fruto de un proceso acumulativo que arranca de los factores estáticos -ventajas comparativas- que determinan la capacidad para atraer $y$ consolidar proyectos empresariales, y se vuelve un proceso dinámico de interacciones en los espacios productivos. Las ventajas iniciales de la región le definen su especialización inicial, pero 
luego van incorporándose características de las economías de índole externa y del crecimiento económico.

Los territorios generan un comportamiento sectorial nacional que responde a comportamientos en el ciclo de vida desde: 1) la localización, el tamaño de la población y el salario promedio industrial, variables que, de acuerdo con los resultados, lo hacen reaccionar de forma directa; 2) el costo laboral unitario y la tasa de desempleo lo hacen reaccionar de forma contraria; 3) la relación capital producto es positiva al ciclo de vida de las firmas en la mayoría de los sectores, excepto en alimentos y bebidas, metálicos y otras industrias manufactureras, lo cual amerita una política de ciencia y tecnología que dé respuesta al tipo de empresas que emergen en cada sector; 4) es importante analizar con detenimiento el signo de la tasa de desempleo frente a la propuesta de política económica donde se plantea que los incentivos empresariales pueden disminuir la tasa de desempleo, y, por último, 5) es importante analizar la relación de salario promedio industrial y costo laboral unitario, que caminan en direcciones contrarias.

Los resultados de la modelación muestran que el grado de heterogeneidad estructural y la poca especialización de algunos sectores y regiones son determinados por distintos factores. Este planteamiento necesita ser tenido en cuenta en el delineamiento de una política industrial que potencie ventajas de cada región para la localización, la especialización y la competencia.

Aunque en el estudio se evidenciaron las relaciones estructurales por regiones y sectores, resultó difícil verificar las relaciones intersectoriales, pues no se establecen parámetros en los que pueda observarse el comportamiento empresarial, el emprendimiento y la dinámica de localización que genera cada territorio a los sectores analizados, asimismo la relación existente de los sectores entre sí y su dinámica en el surgimiento y en la liquidación de las firmas.

Se propuso el modelo con dos variables sociales que reflejan la realidad del territorio colombiano: tasa de homicidio y logro educativo. En la medición que incluía dichas variables se encontró que el segundo podía ser un determinante del surgimiento neto, y que tasa de homicidios no generaba surgimientos netos positivos, como era lo esperado.

Estos resultados, en una propuesta institucional de política industrial, resultan significativos en la medida que la dinámica de sectores productivos no tiene los mismos énfasis ni en los 
sectores ni en las regiones; por lo tanto, las demandas de calificación en tecnologías y recursos son diferentes. Un ejemplo: mientras que costo laboral unitario es negativo al surgimiento neto en Bogotá-Soacha, en Cali-Yumbo y Medellín-Valle de Aburrá es positivo.

¿Cuál es la apuesta, o cuáles son las preocupaciones que tienen que asumirse en términos de los territorios y de los sectores, y cuáles son las razones por las que surgen y se liquidan las empresas en Colombia? Estas son interrogantes que emergen con miras a hacer un aporte a la construcción de políticas para el desarrollo productivo desde los impactos en el territorio y los sectores. En última instancia, la consolidación del ciclo de vida de las firmas lo que hace es fortalecer en su interior a los territorios, y en ellos, a los sectores que allí se localizan. 


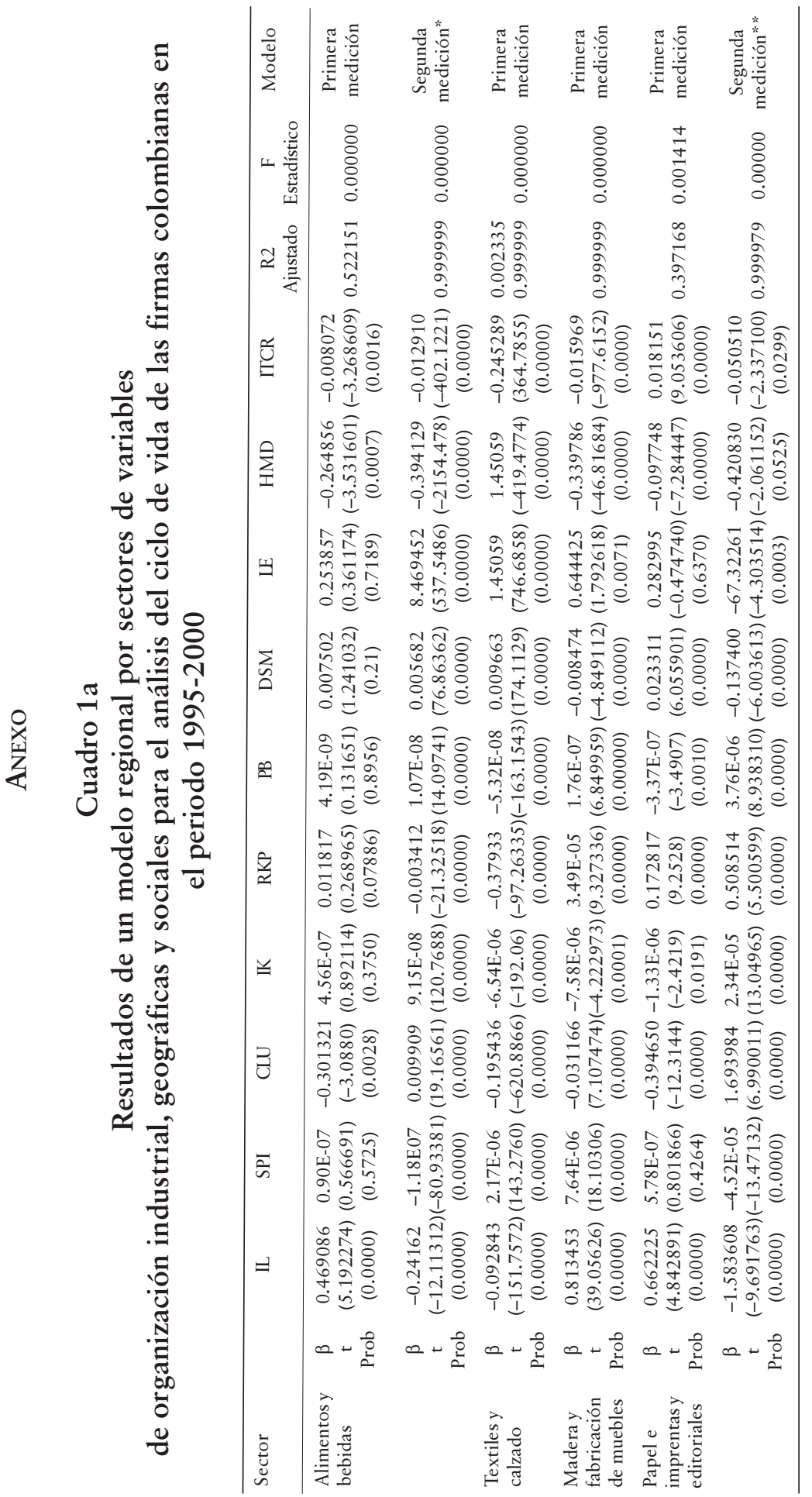




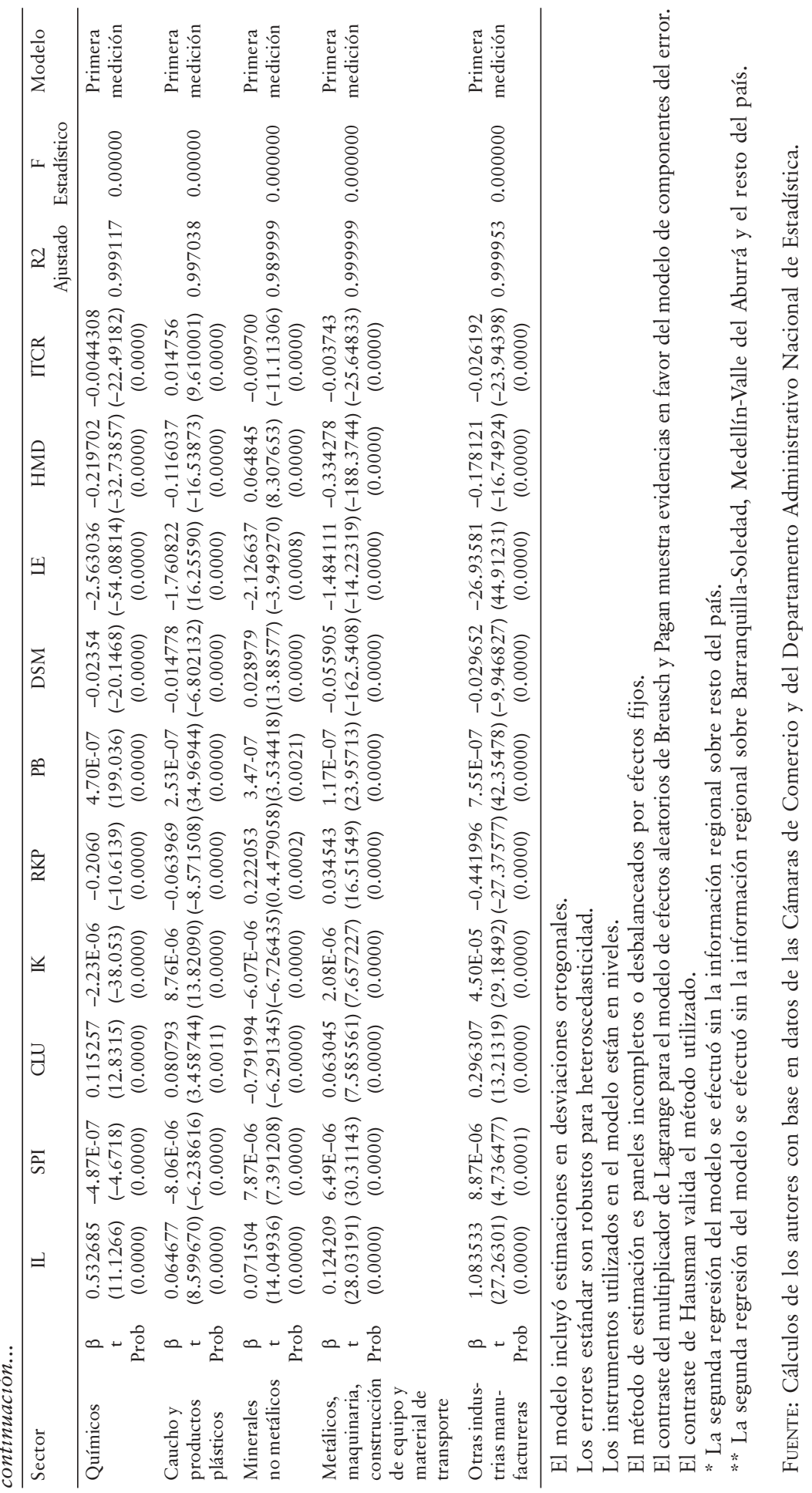




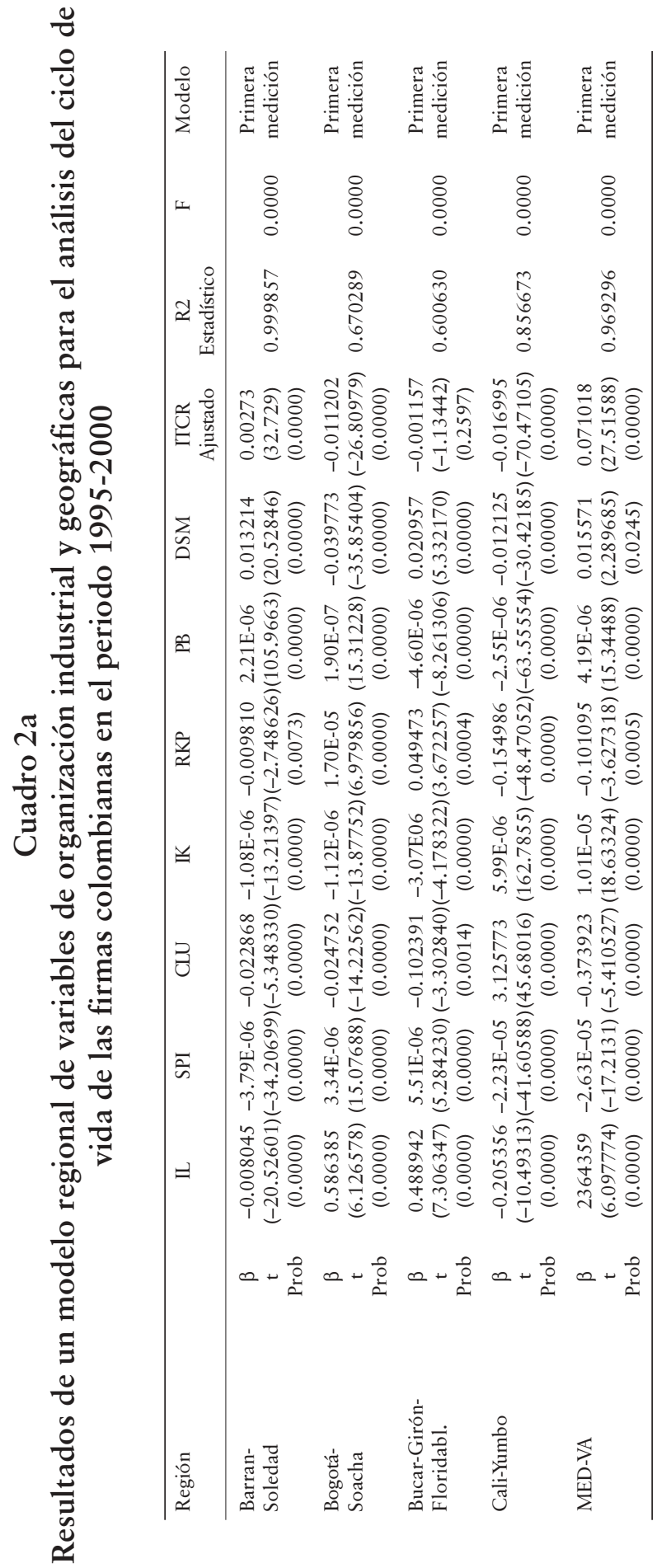




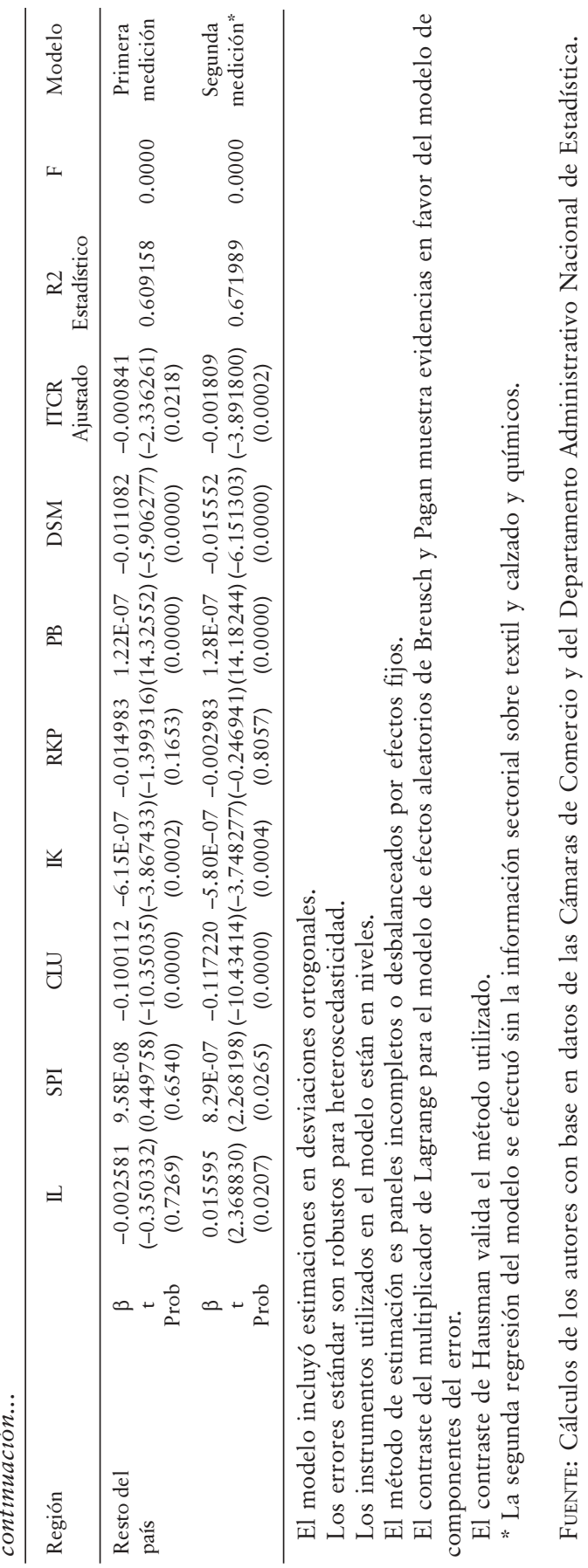




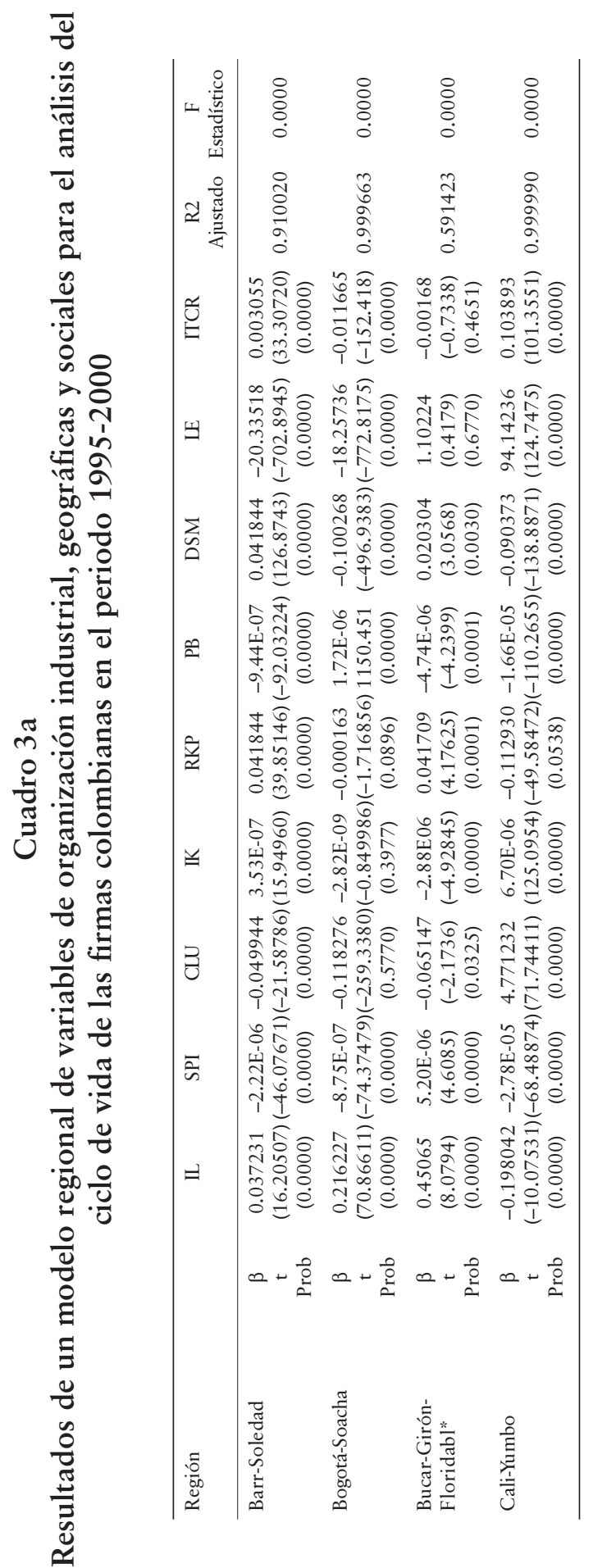




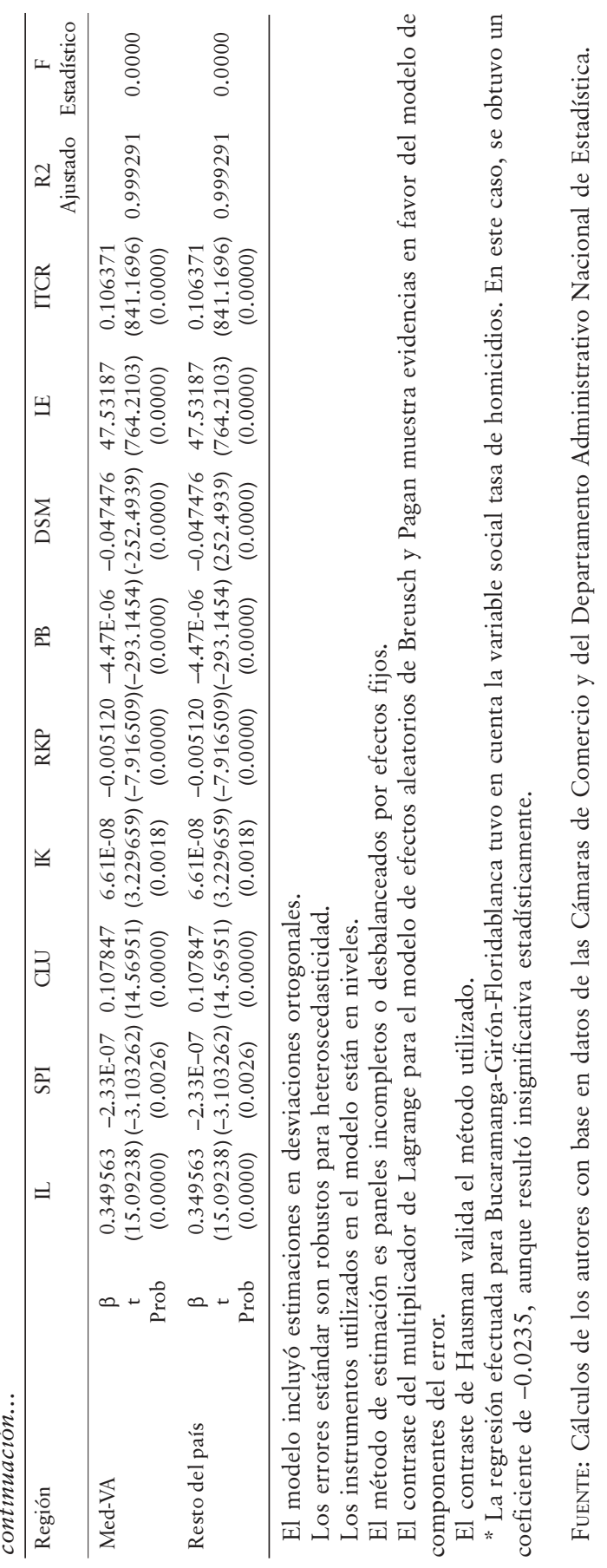




\section{Bibliografía}

Acs, Zoltan J. y David B. Audretsch (1989), "Patents as a Measure of Innovative Activity”, KYKLOS, XLII (2): 171-180.

(1994), "New-Firm Startups, Technology, and Macroeconomic Fluctuations”, Small Business Economics, Springer, 6 (6): 439-449.

(1998). "Innovación, estructura del mercado y tamaño de la empresa", en Hugo Kantis, Gabriel Yoguel et al., Desarrollo y gestión de pymes: aportes para un debate necesario, Universidad Nacional de General Sarmiento, colecc. Libros de la Universidad, Buenos Aires.

Arellano, Manuel y Stephen R. Bond (1991), "Some Test of Specification for Panel Data: Monte Carlo Evidence and an Application to Employment Equations", Review of Economic Studies, 58 (2): 277-297.

y Olimpia Bover (1995), "Another Look at the Instrumental-Variable Estimation of Error-Components Models", Journal of Econometrics, 68 (1): 29-51.

Armington, Catherine y Zoltan Acs (2000), The Determinants of Regional Variation in New Firm Formation, University of Baltimore, Baltimore, MD, octubre.

Audretsch, David B. y Michael Fritsch (1999), "The Industry Component of Regional New Firm Formation Processes", Review of Industrial Organization, 15 (3): 239-252.

Burachik, Gustavo (2000), "Cambio tecnológico y dinámica industrial en América Latina”, Revista de la Cepal, agosto 71: 85-104.

Cardona Marleny y Adriana Ángel (1999), Impacto de las redes industriales en la política sectorial: el caso de los alimentos, textil-confección y metalmecánica, investigación institucional, Universidad Eafit, Medellín, Colombia. 
, Ana Rocío Osorio y Camilo Coronado (2001), Surgimiento de firmas regionales colombianas (1995-2000), investigación institucional, Universidad Eafit, Medellín, Colombia.

, Ana Rocío Osorio y Carlos Andrés Cano (2003), Ciclo de vida y localización espacial de las firmas en Colombia 1995-2000, investigación institucional, Universidad Eafit, Medellín, Colombia.

Cepal (Comisión Económica para América Latina y el Caribe) (2000), “Un crecimiento más dinámico", Equidad, desarrollo y ciudadanía, Naciones Unidas-Cepal, México.

Davidson, Per, Leif Lindmark y Christer Olofsson (1994), "New Firm Formation and Regional Development in Sweden", Regional Studies, 28 (4): 395-410.

Departamento Administrativo Nacional de Estadística (DANE), Encuesta anual manufacturera 1980-2000, Departamento Nacional de Planeación (DNP), Colombia, www.dnp.gov.co.

Durán, Xavier et al. (1998), La innovación tecnológica en Colombia. Características por tamaño y tipo de empresa, DNPColciencias, Bogotá.

Echeverry Garzón, Juan Carlos (1999), “La recesión actual en Colombia: flujos, balances y política anticíclica, Archivos de Macroeconomía, 113, DNP, Unidad de Análisis Macroeconómico, Bogotá.

Feldman, Maryann P. y David B. Audretsch (1998), "Innovation in Cities: Science-Based Diversity, Specialization and Localized Competition", European Economic Review, 43: 409-429.

Greene, William H. (2003), Econometric Analysis, Prentice Hall, Nueva Jersey.

Hansen, Lars Peter (1982), "Large Sample Properties of Generalized Method of Moments Estimator", Econometrica, 50: 1029-1053. 
Keeble, David y Sheila Walker (1994), "New Firms, Small Firms and Dead Firms: Spatial Patterns and Determinants in the United Kingdom”, Regional Studies, 28 (4): 411-427.

Lora, Eduardo (2001), Los obstáculos al desarrollo empresarial y el tamaño de las firmas en América Latina, Banco Interamericano de Desarrollo, Washington, DC.

Lotero, Jorge (1998), "Crisis, reconversión industrial y cambio técnico en el sistema urbano colombiano (1975-1991)”, en Carlos A. de Mattos, Daniel Hiernaux y Darío Restrepo (comps.), Globalización y territorio. Impactos y perspectivas, Pontificia Universidad Católica de Chile-Fondo de Cultura Económica, Santiago de Chile.

Mátyás, László (ed.) (1999), Generalizad Method of Moments Estimation, Cambridge University Press, Cambridge.

Méndez, Ricardo e Inmaculada Caravaca (1996), Organización industrial y territorio, Síntesis, Madrid.

Roper, Stephen y James H. Love (1999), “Determinants of Innovation: R\&D, Technology Transfer and Networking Effects”, Review of Industrial Organization, 15: 43-64.

Schumpeter, Joseph A. (1975), Teoría del desenvolvimiento económico. Una investigación sobre ganancias, capital, crédito, interés y ciclo económico, Fondo de Cultura Económica, México.

Tirole, Jean (1997), The Theory of Industrial Organization, The MIT Press, Massachusetts.

Recibido: 22 de septiembre de 2004. Reenviado: 3 de junio de 2005. Aceptado: 7 de octubre de 2005. 
Marleny Cardona Acevedo es directora del Grupo de Estudios Sectoriales y Territoriales (ESYT) y profesora de la Universidad Eafit de Medellín (Colombia). Economista de la Universidad de Antioquia (Colombia) y doctora en ciencias sociales de El Colegio de la Frontera Norte (México). Entre sus investigaciones más relevantes se encuentran: La cadena productiva como estrategia competitiva en la industria del vestido: los casos de Monterrey y Medellin (1997); Las cadenas productivas como estrategia de competitividad en los sectores: alimentos, textil, confección y metalmecánico (1998); Evaluación del sector floricultor en Colombia (1998); Impacto de las redes productivas en la política sectorial (1999) con Adriana Ángel; Trayectorias profesionales y laborales de los egresados de Administración (2000) con Ana Rocío Osorio y Carlos Londoño; Determinantes en el surgimiento y localización de firmas (2001) con Camilo Coronado; Sociedad en red, innovación y sistemas de información: análisis de caso en las telecomunicaciones y el software para la industria en Colombia (2003); El ciclo de vida y localización espacial de las firmas en Colombia 1995-2000 (2003), y Las mipymes en el crecimiento industrial colombiano 1980-2000 (2004).

Carlos Andrés Cano Gamboa es economista por la Universidad Eafit, Joven Investigador Colciencias (2004), asistente de investigación del Grupo de Estudios Sectoriales y Territoriales ESYT, profesor de Macroeconomía, Microeconomía y Procesos de Investigación Aplicada de la Universidad Eafit de Medellín. Entre sus investigaciones más relevantes se encuentran: El ciclo de vida y localización espacial de las firmas en Colombia 1995-2000 (2003); Las mipymes en el crecimiento industrial colombiano 1980-2000 (2004), Composición, concentración y combinación de factores productivos de las mipymes en la industria colombiana (1980-2000): Un análisis de datos de panel. 